\title{
Study of Coffee Grounds Oil Action in PVC Matrix Exposed to Gamma Radiation: Comparison of Systems in Film and Specimen Forms
}

\author{
Lindomar Avelino da Silva ${ }^{a}$, Tainá Medeiros Bastos de Almeida ${ }^{a}$, Rebeca Valgueiro Teixeira ${ }^{a}$,
}

\author{
Elmo Silvano de Araújo ${ }^{a}$, Kátia Aparecida da Silva Aquino ${ }^{a *}$
}

\author{
${ }^{a}$ Laboratório de Polímeros e Nanoestruturas, Departamento de Energia Nuclear, Universidade Federal \\ de Pernambuco, Recife, PE, Brazil
}

Received: December 11, 2016; Revised: October 08, 2017; Accepted: November 10, 2017

\begin{abstract}
The poly (vinyl chloride), PVC, undergoes changes in its physicochemical properties when it is exposed to gamma radiation. Thus, the radiolytic stabilization of PVC is one way for obtain a material with radiation resistance. In this work, we studied the coffee grounds oil as PVC radiolytic protection in two systems forms: PVC film and PVC specimen. The systems were irradiated at sterilization dose of medical devices and viscosity measurements were performed. According to viscosity assays of PVC films, there was a $67 \%$ protection in polymer matrix promoted by the oil. On the other hand, the mean viscosity molar mass (Mv) of PVC specimens increased about $13 \%$, indicating predominance of crosslinking effect, however samples containing the oil showed no Mv significant changes. Therefore, the oil can be considered a PVC radio stabilizing substance and open a way for use of sustainable additive in PVC industry.
\end{abstract}

Keywords: sustainability, additive, stabilization, polymer.

\section{Introduction}

Recent decades have seen a significant rise in coffee consumption and consequently an increase in the coffee waste generation. Thus, alternative routes are needed for coffee grounds management, developing new treatment or valorization strategies that should be viable both technically and economically. The composition of coffee grounds is very complex as a wide variety of chemical compounds are present, suggesting that this residue can be used for various applications. Kondamudi et al $(2008)^{1}$ recorded a possible valorization of coffee waste route is the production of sugars to be fermented for bioethanol that can be used as fuel or for any other purpose due to its high lignocellulosic content. Caetano et al (2012) ${ }^{2}$ found that coffee grounds have oil content in the order of 10-20 wt $\%$ which can be used for biodiesel. In addition, bioethanol can be used in conjunction with the lipid fraction extracted from coffee to produce biodiesel via a transesterification reaction ${ }^{2}$.

On the other hand, poly (vinyl chloride), PVC, is a polymer widely used for food packaging and medical devices both sterilized by gamma irradiation. However, when the polymer systems are submitted to sterilization by gamma radiation ( $25 \mathrm{kGy}$ dose) their molecular structures undergo modification mainly as a result of main chain scission and crosslinking effects ${ }^{3}$. Both processes coexist for PVC molecules and either one may be predominant depending not only upon the chemical structure of the polymer, but also upon the conditions (temperature, environment, dose rate, etc.) under which irradiation is performed. The crosslinking

"e-mail: aquino@ufpe.br and main scissions that take place during irradiation may lead to sharp changes in physical properties of the $\mathrm{PVC}^{4,5,6}$. Furthermore, $\mathrm{HCl}$ molecules are also released in the radiolytic process. There are some studies about radiolytic stabilization of $\mathrm{PVC}^{7,89}$. For example, Vinhas et al. (2004) $)^{7}$ reported radioprotective action of a common photo-oxidative stabilizer like HALS (Hindered Amine Light Stabilizer) in PVC films plasticized with DEHP (di-2-ethylhexyl phthalate). The HALS additive, is not manufactured to radiation resistance action, but the successful of it use is believed to interrupt oxidative propagation reaction by scavenging of chlorine radical formed in PVC radiolysis. However, no studies that reported the use of vegetable oil as radiolytic protectors of polymers are known. In this way, preparation of PVC films and PVC specimens containing oil extracted from coffee grounds (OCG), which is a discard, has of a great interest and not found data about this proposed system. Films and specimens of PVC with OCG were exposed to gamma irradiation and the effects of the oil on the viscosity average molar mass $\left(\mathrm{M}_{\mathrm{v}}\right)$ of gamma irradiated $\mathrm{PVC}$ were studied. In addition, the free radical scavenger action of OCG, FT-IR spectrum, and mechanical properties of PVC with OCG, for both forms, were discussed in this study.

\section{Experimental}

\subsection{Coffee grounds samples and oil extraction}

Coffee grounds samples were obtained from residencies located in Recife/PE, Brazil. The samples were dehydrated 
at $60^{\circ} \mathrm{C}$ during $24 \mathrm{~h}$. Once dried, they were manually crushed and ground and stored at $18^{\circ} \mathrm{C}$ temperature until use.

Oil extraction from dried coffee grounds was performed in a soxhlet apparatus utilizing $\mathrm{n}$-hexane as solvent. The $8 \mathrm{~h}$ extraction was carried out for total removal of oil. Solvent was removed from the resulting product using a simple distillation at $60^{\circ} \mathrm{C}$. The oil was kept away from light and air at $18^{\circ} \mathrm{C}$ until processing and analysis took place.

\subsection{Preparation of $P V C$ films and PVC specimens}

The studied polymer material was commercial PVC (BRASKEM, Brazil). The films ( $\approx 60 \mu \mathrm{m}$ thickness) of PVC and PVC with addition of OCG (PVC/OCG) were prepared by solvent-casting from methyl-ethyl-ketone (MEK) solvent by slow evaporation in air at room temperature $\left(\approx 27^{\circ} \mathrm{C}\right)$ upon $48 \mathrm{~h}$ of magnetic stir of the polymer solution $(1,8 \mathrm{~g}$ of the PVC/40 mL of the MEK). MEK was dried with $\mathrm{Na}_{2} \mathrm{SO}_{4}$ and purified by distillation.

On the other hand, the PVC and PVC/OCG specimen samples were produced by BRASKEM, Brazil. The Norvic SP 1300FA resin $(K=71)$ was used for the production of PVC specimens. The resin was mixed (Mecanoplast mixer, 9 liter ML9, $1200 \mathrm{rpm}$ ) with solid additives as the thermal stabilizers, at room temperature $\left(\approx 27^{\circ} \mathrm{C}\right)$. Then the mixture was heated and at $80^{\circ} \mathrm{C}$ the liquid additives as plasticizer Dioctyl Phthalate and OCG were added. The blend was processed on a two roll calender at a temperature of $150{ }^{\circ} \mathrm{C}$ for 3 minutes (20 rpm). Then, the specimens were pressed in Luxor press with a pressure of $100 \mathrm{Kgf} / \mathrm{cm}^{2}$ for $2 \mathrm{~min}$ and a pressure of $200 \mathrm{Kgf} / \mathrm{cm}^{2}$ for 1 minute, consecutively. Afterwards, the PVC specimens were cooled to $40^{\circ} \mathrm{C}$ and they were cut in tie-type IV dimensions of standard ASTM-D $638(\approx 3 \mathrm{~mm}$ thickness). According the manufacturer, the specimens were produced for medical applications (catheter). They were processed with additives as plasticizers, lubricants, and thermal protectors. For both systems the concentrations of OCG used was $0.50 \mathrm{wt} \%$. This concentration was obtained in ours previous study ${ }^{10}$.

\subsection{Viscosity measurements}

The viscosity measurements of PVC and PVC/OCG samples were carried out in THF solution at $25.0 \pm 0.1^{\circ} \mathrm{C}$ using an Ostwald viscometer in a thermostatic bath. The intrinsic viscosity of the samples was calculated from the relative viscosity, $\eta_{\text {rel }} \approx v / v_{0} \approx t / t_{0}$, within range of $1.1-1.9$, where $v$ and $v_{0}$ are the cinematic viscosities on the polymer solution and the solvent, respectively. The $t$ and $t_{0}$ are flow times of solution and solvent, respectively. Therefore, $\eta_{\text {rel }}$ was calculated from $t / t_{0}$ ratio. The specific viscosity $\left(\eta_{\mathrm{sp}}=\right.$ $\left.\eta_{\text {rel }}-1\right)$ and the reduced viscosity $\left(\eta_{\text {red }}=\eta_{\text {sp }} / C\right)$, where $C$ is the concentration of the solution $(0.6 \mathrm{~g} / \mathrm{dL})$, were calculated as well. The intrinsic viscosity [ $\eta]$ was determined by the Solomon-Ciuta equation ${ }^{8,11}$. The viscosity average molar mass, $M_{v}$, was then calculated from the corresponding $[\eta]$ values trough the Mark-Houwink equation $\left([\eta]=K \mathrm{M}_{\mathrm{v}}{ }^{a}\right)^{12}$. For Mark-Houwink equation, $K$ and $a$ are $1.5 \times 10^{-4} \mathrm{dL} / \mathrm{g}$ and 0.766 , respectively for the THF-PVC system at $25^{\circ} \mathrm{C}^{13}$.

Radio stabilizing action of OCG on PVC matrix can be assessed by comparison of degradation index (DI) parameter, $\mathrm{DI}=\left(\mathrm{M}_{\mathrm{vo}} / \mathrm{M}_{\mathrm{v}}\right)-1$, for a determined irradiation dose. The $\mathrm{M}_{\mathrm{v} 0}$ and $\mathrm{M}_{\mathrm{v}}$ are the viscosity average molar mass before and after the gamma irradiation, respectively. DI is obtained from viscosity analysis and reflects the number of main chain scissions per original molecule after irradiation.

\subsection{Irradiation of samples}

The samples were exposed to gamma radiation from a ${ }^{60} \mathrm{Co}$ source (dose rate of $6.13 \mathrm{kGy} / \mathrm{h}$ ) at dose of $25 \mathrm{kGy}$ (sterilization dose) in presence of atmosphere air and at room temperature $\left(\approx 27^{\circ} \mathrm{C}\right)$.

\subsection{Free radical scavenger action of the coffee grounds oil}

The efficiency of OCG to scavenge the 2,2-diphenyl-1(2,4,6-trinitrophenyl)-hydrazyl radical (DPPH) was determined in this study. The standard reaction consists in the mixture $0.0024 \mathrm{~g}$ of the DPPH in the $100 \mathrm{~mL}$ of ethanol. Appropriate amount of oil was mix with the DPPH solution and the system must be vigorously agitated. The reaction was carried out at ambient temperature $\left(\approx 27^{\circ} \mathrm{C}\right)$ for $30 \mathrm{~min}$. The absorbance at $515 \mathrm{~nm}$ was measured against a blank of pure ethanol after the reaction in a UV-vis spectrophotometer Spectro 22, 108-D and $60 \mathrm{~Hz}$. Radical DPPH scavenging capacity (\%SC) was estimated from the difference in absorbance with or without OCG (equation 1).

$$
\% S C=\frac{A s-A s n}{A s} \times 100
$$

Where $\mathrm{A}_{\mathrm{s}}=\mathrm{DPPH}$ solution absorbance and $\mathrm{A}_{\mathrm{sn}}=\mathrm{DPPH}$ solution absorbance for system with OCG. BHT (2,6-bis(1,1dimethylethyl)-4-methylphenol) was used as positive control. All tests were conducted in triplicate.

\section{6 FT-IR characterization}

Infrared spectra of PVC and PVC/OCG samples were obtained by Fourier Transform Infrared Spectroscopy (Bruker-IFS66), equipped with an attenuated total reflection accessory (FTIR-ATR), in the $4000-400 \mathrm{~cm}^{-1}$ wavenumber region, 75 scans per spectrum, with $4 \mathrm{~cm}^{-1}$ resolution.

\subsection{Mechanical properties}

The tensile properties of the PVC film samples were determined according to ASTM D-882 using an Instron machine IMIC, DL-500 N. The crosshead speed was 3 $\mathrm{mm} / \mathrm{min}$. The tests were carried out at room temperature $\left(\approx 27^{\circ} \mathrm{C}\right)$ and the results shown in this study are an average of four samples with sample dimension of $2.5 \times 7.5 \mathrm{~cm} \mathrm{x}$ $0.11 \mathrm{~mm}$. On the other hand, the tensile properties of PVC 
specimen samples were determined according ASTM D-638, four samples and using similar machine used for PVC film samples. Assays were performed under the following conditions: load cell of $500 \mathrm{~N}$, crosshead speed of $2 \mathrm{~mm} /$ $\min$, and at room temperature $\left(\approx 27^{\circ} \mathrm{C}\right)$.

\section{Results and Discussions}

\subsection{Radiolytic action of coffee grounds oil in PVC matrix}

The oil content of the coffee (Coffea arabica L) grounds was calculated to $10 \%$ and are comparable to the ones for commercial vegetable oils like soybean $(11-25 \%)^{14}$. The oil was incorporated in the PVC matrix and were formed a homogeneous material for both PVC film and PVC specimens. After irradiation a yellow color was observed for all systems.

Radio stabilizing results are shown in Table 1 that shows $M_{v}$ for the PVC systems before and after irradiation. The results revealed that $\mathrm{M}_{\mathrm{v}}$ decreased for irradiated PVC films and increased for PVC specimens. In radiolysis process may occurs the scission and the crosslinking effects of polymeric materials. The formation of unsaturated linking, formation of gasses, and low molecular weight products also are generated by radiolysis ${ }^{4,5}$.

Ours results for PVC film showed the predominance of main chain scission, in agreement with the literature that reports about gamma radiation effects on the PVC matrix ${ }^{4,5,7}$. However, the analysis of Table 1 revealed less chain scissions occur in $\mathrm{PVC} / \mathrm{OCG}$ films at $0.50 \mathrm{wt} \%$ concentration. At sterilization dose $(25 \mathrm{kGy})$ we calculated $\mathrm{DI}=0.126$ for $\mathrm{PVC}$ and $\mathrm{DI}=0.041$ for $\mathrm{PVC} / \mathrm{OCG}$ films. These data represent a decrease $67 \%$ in scissions per original molecule of PVC.

On the other hand, according Table 1, the PVC specimens undergoes an increase of $13 \%$ on $\mathrm{Mv}$ and it represents the crosslinking as main effect in the PVC chain. The PVC specimens have larger thickness than PVC film then it is probable that larger section interacting with radiation which can contribute to increased formation of radiation products. In next step, these products seem to suffer predominantly radiation crosslinking effect, which leads to increased $\mathrm{Mv}$. In addition, the antioxidant additives phenolic and phosphate usually presents in PVC plasticized, undergo preferably degradation in the processes of irradiation because of the partial radiolysis ${ }^{15,16}$. Thus, PVC specimens are more sensitive to the conditions of irradiation and more susceptible to oxidative degradation than the own resins which not contain additives like the PVC film. However, no significant event (scission or crosslinking effects) was found for PVC/OCG specimens systems. This result, open an important way for radiolytic stabilization of PVC by use of sustainable additive.

In addition, the Mv of PVC specimen are lower than Mv of PVC film. These results imply decreases in intrinsic viscosity, which are results of the contraction of PVC molecule coil in solution. The molecules of some additives can cause the contraction of the PVC molecules due to lack of chemical affinity, for example. Thus, the contracted PVC coil (in PVC specimens) yields a lower hydrodynamic volume, which facilitated the passage of the polymer solution through the viscometer capillary tube and decrease its viscosity.

On the other hand, further evidences on intermolecular interactions between PVC and OCG also could be assessed by viscosity analysis. The Table 1 shows an increase in $M_{v}$ for PVC/OCG for both film and specimen systems. These increases in $\mathrm{M}_{\mathrm{v}}$ means expansion of PVC molecule coil in solution, most probably due to interactions of some OCG group and chlorine of PVC molecule by dipole-dipole interaction and cause expansion of molecule with increasing viscosity. Nevertheless, further discussions about molecular interactions between the OCG and PVC will be presented by FT-IR analyses.

To the best of our knowledge, no information about use of OCG in the radiolytic stabilization of polymers has been published and consequently the mechanism of radiolytic stabilization effect of this oil is not clear. However, some probable reactions may occur when the polymer system is exposed to gamma irradiation. The gamma rays can break covalent bonds in PVC molecule to directly produce the free radicals ${ }^{17,18}$. The efficiency of certain composts in the stabilization of polymer molecules against radiation may be evaluated by measuring theirs effect on the free radical population after irradiation, as well as on its rate of decay. The Table 2 shows the results obtained by use of OCG as a scavenger free radical on the DPPH solution.

Table 1. Viscosity results obtained for PVC/OCG

\begin{tabular}{lcccc}
\hline Systems & Dose (kGy) & Mv (g/mol) & Main event & ID (\%) \\
\hline \multirow{2}{*}{ PVC (film) } & 0 & $63,874 \pm 1,399$ & scission & 0.126 \\
& 25 & $56,732 \pm 1,767$ & & 0.041 \\
PVC/OGC (film) & 0 & $68,666 \pm 1,121$ & scission & - \\
PVC (specimen) & 25 & $65,960 \pm 1,420$ & & \\
& 0 & $41,310 \pm 385$ & crosslinking & - \\
PVC/OGC (specim en) & 25 & $46,898 \pm 244$ & no event & \\
\hline
\end{tabular}


Table 2. Radical DPPH scavenging capacity (SC) results

\begin{tabular}{lcc}
\hline Systems & Absorbance $(515 \mathrm{~nm})$ & $\mathrm{SC}(\%)$ \\
\hline DPPH puro & $1.24 \pm 0.02$ & - \\
DPPH + OGC & $1.23 \pm 0.02$ & - \\
& & $72.58 \pm$ \\
DPPH + BHT & $0.34 \pm 0.06$ & 0.7 \\
\hline
\end{tabular}

DPPH is a stable free radical, non-natural, and it can react with another free radical. The DPPH solution presenting a strong absorption at visible spectrum in wavelength of 515 $\mathrm{nm}$, characterized by an intense violet coloration, due to the presence of free electrons (Fig. 1a). When the DPPH is in the presence of substances able to scavenge free radicals, the absorption is inhibited, leading to a stoichiometric discoloration in relation to the number of reduced molecules of $\mathrm{DPPH}^{19,20}$. The degree of discoloration is directly correlated with the free radical scavenger activity of the evaluated substance $e^{21,22}$.

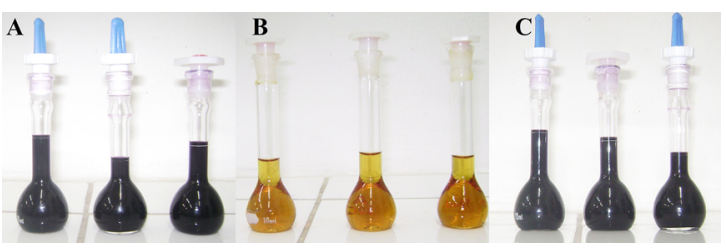

Figure 1. Results obtained for: a) DPPH solution; b) DPPH+BHT and c) $\mathrm{DPPH}+\mathrm{OCG}$

Ours results reveal that OCG in the amount of $0.0090 \mathrm{~g}$ (equivalent to concentration of $0.5 \mathrm{wt} \%$ in PVC matrix) not have scavenger free radical action because the DPPH+OCG solution showed no discoloration (Fig. 1c). On the other hand, the positive control of BHT exhibited radical scavenging capacity by solution discoloration (see Fig. 1b).

Thus, the mechanism proposed to action of OCG in the PVC matrix is by Quencher action. Quencher stabilizer acts dissipating the excess energy by fluorescence, phosphorescence, or conversion to heat, instead of letting it break chemical bonds. Then the OCG molecule causes a decrease in the formation of free radicals, which are responsible for scission degradation or crosslinking reaction. The possible mechanism is represented on the scheme 1 .

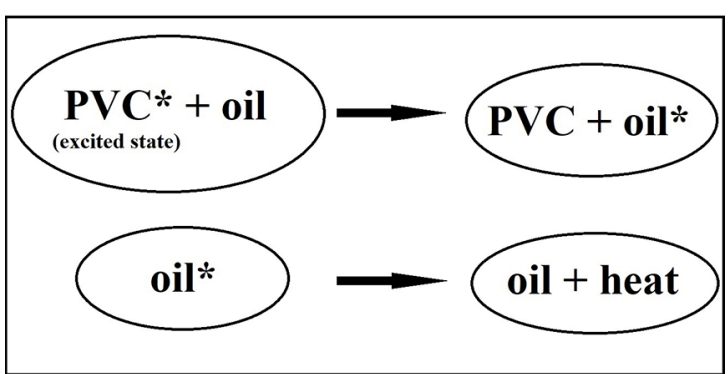

Scheme 1. Proposed mechanism of OCG action in PVC molecule exposed to gamma irradiation
We assumed the quencher stabilizer is the principal function of the OCG on the PVC films and PVC specimens, but further work is required to providing a better understanding of all processes involved in the radiolytic action of the oil on PVC matrix.

\subsection{Characterization of the PVC film and PVC specimen}

FT-IR spectroscopy was used to detect and identify the presence of intermolecular interactions between PVC and OCG molecules. The existence of specific $\mathrm{C}-\mathrm{Cl}$ oil interactions in the PVC/OCG system could be inferred from a shift in $\mathrm{C}-\mathrm{Cl}$ stretching vibrations with the presence of OCG or other changes such as broadening of the $\mathrm{C}-\mathrm{Cl}$ stretching peak or its intensity change, and even a new peak formation ${ }^{23,24}$.

Figure 2 shows FT-IR spectra of PVC and PVC/OCG for non-irradiated and irradiated films in the 4000-500 $\mathrm{cm}^{-1}$ wavenumber for PVC film (2a) and PVC specimens (2b). The band assignments for all systems (irradiated and nonirradiated) of PVC and PVC/OCG are listed in Table 3.

It can be observed in the spectra of PVC specimen (Figure 2a) and spectra of PVC film (Figure 2b) that OCG addition is not easily visually detected, because the positions of absorbance peaks are similar. However, according Table 2, the vibrational peaks assignment to $\mathrm{C}-\mathrm{Cl}$ stretching of $\mathrm{PVC}$ are shifted in PVC/OCG for both PVC specimen and PVC film systems. Moreover, the peak of PVC specimens at $1423 \mathrm{~cm}^{-1}$ has changed from two sharp peaks at 1423 and $1460 \mathrm{~cm}^{-1}$ in PVC/OCG specimen for non-irradiated system, for example. Similar behavior was observed for $1354 \mathrm{~cm}^{-1}$ absorption in PVC specimen (non-irradiated). This peak has from two sharp peaks at 1356 and $1381 \mathrm{~cm}^{-1}$ in PVC/ OCG specimen. The assignments of additional peaks are showed in Table 2. The change in shape and position of the peaks confirms that interactions occurred between PVC and OCG molecules ${ }^{25}$. On the other hand, the spectra obtained for irradiated samples do not showed significant changes.

In addition, the $\mathrm{C}=\mathrm{O}$ vibration was observed in the systems, except the irradiated PVC/OCG film. In case of films, the vibration may be attributed to residual solvent (methyl-ethyl-ketone) used in the casting production of samples. However, for PVC specimens, the additives, like plasticizers, are incorporate in the polymer matrix and $\mathrm{C}=\mathrm{O}$ vibration may be assignment to these molecules. The confirmation is the presence of peak assignment to $\mathrm{C}-\mathrm{O}-\mathrm{C}$ axial vibration only in the $\mathrm{PVC} / \mathrm{OCG}$ specimen spectrum (see Table 3).

\subsection{Mechanical properties}

The results of mechanical measurements for PVC and PVC/OCG are summarized in Table 4. The properties studied were elongation at break (Eb) and Young's modulus (Ym). The mean values of the mechanical properties were 

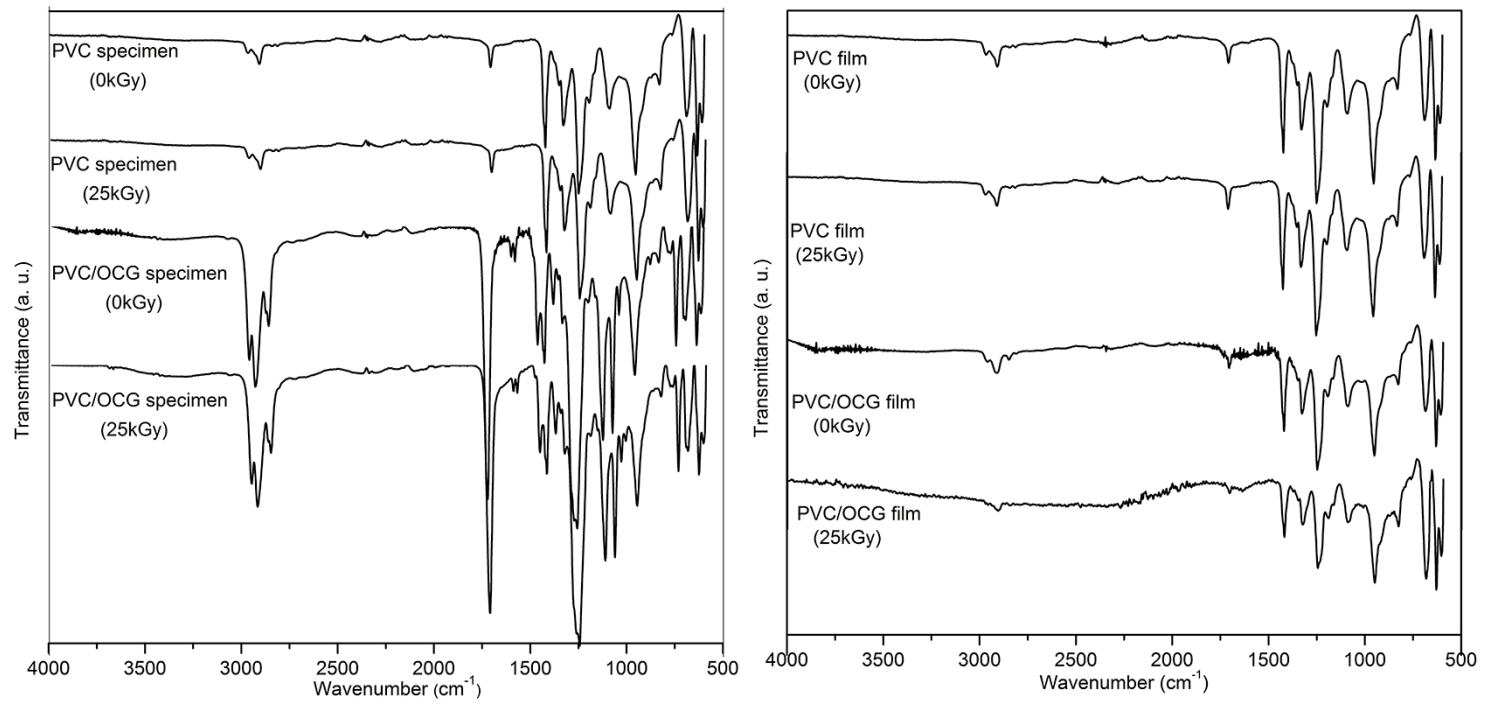

Figure 2. FT-IR spectra obtained for a) PVC specimen and b) PVC film

Table 3. Peak assignments for FT-IR spectra of PVC and PVC/OCG systems

\begin{tabular}{|c|c|c|c|c|c|c|c|c|}
\hline \multicolumn{8}{|c|}{ Absorption peak $\left(\mathrm{cm}^{-1}\right)$} & \multirow[b]{3}{*}{ Peak assignment } \\
\hline \multicolumn{4}{|c|}{ Specimens } & \multicolumn{4}{|l|}{ Films } & \\
\hline $\begin{array}{c}\text { PVC } \\
(0 \mathrm{kGy})\end{array}$ & $\begin{array}{l}\text { PVC } \\
(25 k G y)\end{array}$ & $\begin{array}{l}\text { PVC/ } \\
\text { OGC } \\
(0 k G y)\end{array}$ & $\begin{array}{l}\text { PVC/ } \\
\text { OGC } \\
(\mathbf{2 5 k G y )}\end{array}$ & $\begin{array}{l}\text { PVC } \\
(0 \text { kGy) }\end{array}$ & $\begin{array}{l}\text { PVC } \\
(25 \text { kGy })\end{array}$ & $\begin{array}{l}\text { PVC/ } \\
\text { OGC } \\
(0 \text { kGy) }\end{array}$ & $\begin{array}{l}\text { PVC/ } \\
\text { OGC } \\
(25 \text { kGy) }\end{array}$ & \\
\hline 2971 & 2970 & 2959 & 2961 & 2967 & 2971 & 2964 & 2965 & $\begin{array}{l}\mathrm{CH} \text { stretch, out of phase, on } \\
\text { neighboring } \mathrm{CHCl} \text { groups }\end{array}$ \\
\hline 2910 & 2912 & $\begin{array}{l}2925 \\
2850\end{array}$ & $\begin{array}{l}2927 \\
2852\end{array}$ & 2912 & 2909 & 2915 & 2912 & $\begin{array}{c}\mathrm{CH}_{2} \text { stretch, asymmetrical, in } \\
\text { phase }\end{array}$ \\
\hline 1718 & 1719 & 1722 & 1720 & 1712 & 1710 & 1709 & - & $\mathrm{C}=\mathrm{O}$ axial, carbonyl group \\
\hline- & - & 1460 & 1462 & - & - & - & - & $\mathrm{CH}_{2}$ bend \\
\hline 1423 & 1423 & 1423 & 1424 & 1428 & 1427 & 1426 & 1426 & $\mathrm{CH}_{2}$ bend, in phase \\
\hline- & - & 1381 & 1383 & - & - & - & - & $\mathrm{C}-\mathrm{H}$ bend, $\mathrm{CH}_{3}$ bond \\
\hline 1354 & 1354 & 1356 & 1356 & 1354 & 1354 & 1354 & 1354 & $\mathrm{CH}_{2}$ wag, in phase \\
\hline 1337 & 1331 & 1334 & 1333 & 1333 & 1332 & 1331 & 1329 & $\mathrm{C}-\mathrm{H}$ bend of $\mathrm{CHCl}$, out of phase \\
\hline 1258 & 1253 & 1267 & 1266 & 1252 & 1252 & 1254 & 1250 & $\mathrm{C}-\mathrm{H}$ bend of $\mathrm{CHCl}$, in phase \\
\hline 1196 & 1192 & 1191 & 1198 & - & - & - & - & C-O-C axial, asymmetrical \\
\hline 1120 & 1121 & 1121 & 1123 & 1120 & 1120 & 1122 & 1122 & $\mathrm{CH}$ wag, out of phase \\
\hline 1094 & 1093 & 1094 & 1092 & 1096 & 1094 & 1096 & 1093 & C-C stretch, perpendicular \\
\hline 956 & 956 & 957 & 957 & 957 & 957 & 957 & 955 & $\mathrm{CH}_{2}$ rocking \\
\hline 831 & 832 & 840 & 841 & 832 & 832 & 832 & 832 & C-C stretch \\
\hline $\begin{array}{c}690 \\
638,611\end{array}$ & $\begin{array}{c}689 \\
634,610\end{array}$ & $\begin{array}{c}700 \\
647,615\end{array}$ & $\begin{array}{c}704 \\
638,612\end{array}$ & $\begin{array}{c}696 \\
638,615\end{array}$ & $\begin{array}{c}692 \\
636,612\end{array}$ & $\begin{array}{c}687 \\
632,609\end{array}$ & $\begin{array}{c}688 \\
631,608\end{array}$ & C-Cl stretch \\
\hline
\end{tabular}

compared statistically by Student's t-test, with a significance level of $5 \%(p<0.05)$.

Analyzing first the PVC films non-irradiated it was found that the value of $\mathrm{Ym}$ for PVC/OCG decreases 3\% when compared with the $\mathrm{Ym}$ value of PVC. This result means a decrease in rigidity of the $\mathrm{PVC}$ film and consequently explains the increase of $9 \%$ on Ea value of PVC/OCG. Generally, PVC shows dipole-dipole attraction as a result of the electrostatic interactions between the chlorine atom of one polymer chain (negative pole) and the hydrogen atom of another polymer molecule (positive pole). Intermolecular interactions between PVC and OCG were discussed by FT-IR analyses. These interactions could be weakened by special action of OCG, which promote decrease in the density of entanglements points of the polymer molecules. In addition, it was found a decrease of $26 \%$ in $\mathrm{Ym}$ value with consequent increase 
Table 4. Effects of OCG ( $0.5 \mathrm{wt} \%)$ and gamma irradiation in the mechanical properties of PVC

\begin{tabular}{lccc}
\hline System & $\begin{array}{c}\text { Dose } \\
\text { (kGy) }\end{array}$ & Ym (MPa) & Eb (\%) \\
\hline PVC film & 0 & $913.33 \pm 82.24^{\mathrm{a}}$ & $7.43 \pm 0.83^{\mathrm{a}}$ \\
& 25 & $674.23 \pm 61.08^{\mathrm{b}}$ & $8.89 \pm 0.43^{\mathrm{b}}$ \\
PVC/OGC & 0 & $883.05 \pm 73.98^{\mathrm{c}}$ & $9.17 \pm 0.43^{\mathrm{c}}$ \\
film & 25 & $746.30 \pm 54.78^{\mathrm{c}}$ & $9.73 \pm 0.25^{\mathrm{c}}$ \\
PVC & 0 & $0.106 \pm 0.022^{\mathrm{d}}$ & $295.59 \pm 18.41^{\mathrm{d}}$ \\
specimen & 25 & $0.107 \pm 0.011^{\mathrm{d}}$ & $293.42 \pm 5.53^{\mathrm{d}}$ \\
PVC/OGC & 0 & $0.103 \pm 0.011^{\mathrm{e}}$ & $336.85 \pm 21.94^{\mathrm{e}}$ \\
specimen & 25 & $0.126 \pm 0.048^{\mathrm{f}}$ & $261.75 \pm 11.28^{\mathrm{f}}$ \\
\hline
\end{tabular}

Means with the same letter in the same column do not differ with $\mathrm{p}<0.05$ for the Student's t-test.

of $16 \%$ in Eb value for PVC films irradiated at $25 \mathrm{kGy}$. The chain scission effect obtained by gamma irradiation (Table 1) provokes the decrease of average length of PVC molecule. The density of entanglements points decreases leading to a decrease of the $\mathrm{Ym}$ value as consequence of PVC radiolytic degradation. The lower molecular weight also makes fibrils less stable and therefore favors brittle fracture ${ }^{12,17}$. On the other hand, decrease of $15 \%$ in Ym value and less influence in Eb were found for irradiated PVC/OCG. These results are explained by stabilizer action of OCG in the PVC matrix and agree with the viscosity measurements.

Similar results were found for non-irradiated PVC specimens, i. e., the OCG provoke decrease in rigidity of polymer with decrease of Ym value and consequent increase of percentage of elongation. The results also showed a good radiation resistance of PVC specimens, unlike PVC in film form systems, since the radiation does not influence significantly their mechanical properties. On the other hand, increase of $\mathrm{Ym}$ and decrease of Ea values were found in PVC/OCG specimens as effect of radiation. It should be noted that the results shown in Table 4 reveal a fairly plasticized material due to the low Ym value and consequent high Eb value. The large amount of plasticizer and other additives in the polymer matrix must have influenced the non-significant action of OCG on the mechanical properties of PVC specimens.

\section{Conclusions}

The oil content in the coffee (Coffea arabica L) grounds was calculated to $10 \%$. This oil was added in $\mathrm{PVC}$ matrix to form two systems: the PVC/oil films and PVC/ oil specimens. The viscosity analyses suggest that oil $(0.5$ $\mathrm{wt} \%$ ) protected PVC for both forms against radiolysis by Quencher mechanism. The FT-IR analyses showed specifics molecular interactions between PVC and oil molecules. The incorporation of coffee ground oil in PVC film influenced directly its mechanical properties. The material in film form has become more plasticized and the gamma irradiation undergoes less damage in its mechanical properties. On the other hand, great mechanical resistance of PVC specimens was found and no-significant action of oil was found for these systems.

Our results confirmed, which the polymer industry can produce materials with sustainable additives and applications that require resistance to gamma radiation. The pioneering nature of our study opens a fruitful path for new studies that use discards to generate a positive impact on the environment and on polymer science.

\section{Acknowledgments}

We would like to thanks for BRASKEM-Brazil for PVC samples and FACEPE for financial support.

\section{References}

1. Kondamudi N, Mohapatra SK, Misra M. Spent Coffee Grounds as a Versatile Source of green energy. Journal of Agriculture and Food Chemistry. 2008;56(24):11757-11760.

2. Caetano NS, Silva VFM, Mata TM. Valorization of Coffee Grounds for Biodiesel Production. Chemical Engineering Transactions. 2012;26:267-272.

3. Charlesby A. Atomic radiation and polymers. New York: Pergamon Press; 1960.

4. Vinhas GM, Souto-Maior RM, Almeida YMB, Neto BB. Radiolytic degradation of poly(vinyl chloride) systems. Polymer Degradation and Stability. 2004;86(3):431-436.

5. Mendizabal E, Cruz L, Jasso CF, Burillo G, Davin VI. Radiation crosslinking of highly plasticized PVC. Radiation Physics and Chemistry. 1996;47(2):305-309.

6. Dole M. The Radiation Chemistry of Macromolecules. New York: Academic Press; 1973.

7. Vinhas GM, Souto-Maior RM, Almeida WMB. Radiolytic degradation and stabilization of poly(vinyl choride). Polymer Degradation and Stability. 2004;83(3):429-433.

8. da Silva WB, Aquino KAS, de Vasconcelos HM, Araujo ES. Influence of copper chloride and potassium iodide mixture in poly(vinyl chloride) exposed to gamma irradiation. Polymer Degradation and Stability. 2013;98(1):241-245.

9. Khang G, Kong CS, Rhee JM, Lee HB. Stabilization of nontoxic PVC formulation for gamma irradiation sterilization, I. Effect of additives. Bio-Medical Materials and Engineering. 2002;12(2):135-147.

10. Lima TA, Aquino KAS, Araújo ES. Effect of oil extracted from coffee grounds in the radiolytic stabilization of PVC. In: Anals of the $6^{\text {th }}$ International Nuclear Atlantic Conference - INAC 2013; 2013 Nov 24-29; Recife, PE, Brazil. Available from: $<$ http://www.iaea.org/inis/collection/NCLCollectionStore/_ Public/46/004/46004070.pdf $>$. Access in: 08/12/2016.

11. Cragg LH, Bigelow CC. The viscosity slope constant $k$ '-ternary systems: Polymer-polymer-solvent. Journal of Polymer Science Part A Polymer Chemistry. 1955;16(82):177-191. 
12. Guillet J. Polymer photophysics and photochemistry. Cambridge: Cambridge University Press; 1985.

13. Brandrup J, Immergut EH, eds. Polymer Handbook. $3^{\text {rd }}$ ed. New York: John Wiley and Sons; 1989.

14. Ajiwe VIE, Umerie SC, Okeke CA, Oburota VN. Extraction and utilisation of cassava seed oil. Bioresource Technology. 1994;47(1):85-86.

15. Goulas AE, Righanakos KA, Kontominas MG. Effect of ionizing radiation on physicochemicaland mechanical properties of commercial monolayer and multilayer semirigid plastics packaging materials. Radiation Physics and Chemistry. 2004;69(5):411-417.

16. Demertzis PG, Franz R, Welle F. The effects of $\gamma$-irradiation on compositional changes in plastic packaging films. Packaging Technology and Science. 1999;12(3):119-130.

17. Baccaro S, Brunella V, Cecilia A, Costa L. $\gamma$ irradiation of poly(vinyl choride) for medical applications. Nuclear Instruments and Methods in Physics Research Section B: Beam Interactions with Materials and Atoms. 2003;208:195-198.

18. Cottrel TL. The Strengths of Chemical Bonds. London: Butterworths; 1954.

19. Walling C. Free Radicals in Solution. New York: John Wiley and Sons; 1957.
20. Leopoldini M, Marino T, Russo N, Toscano M. Antioxidant Properties of Phenolic Compounds. H-Atom versus Electron Transfer Mechanism. Journal of Physical Chemistry A. 2004;108(22):4916-4922.

21. Mathiesen L, Malterud KE, Sund RB. Hydrogen bond formation as basis for radical scavenging activity: a structure-activity study of C-methylated dihydrochalcones from Myrica gale and structurally related acetophenones. Free Radical Biology and Medicine. 1997;22(1-2):307-311.

22. Ionita P, Constantinescu T, Caldararu H, Luca C, Caproiu MT, Dumitrascu F, et al. Reaction between the DPPH free radical and potassium cyanide in the presence of crown ether 18-C-6: a correction. Revue Roumaine de Chimie. 1999;44:393-396.

23. Muyonga JH, Cole CGB, Duodu KG. Fourier transform infrared (FTIR) spectroscopic study of acid soluble collagen and gelatin from skins and bones of young and adult Nile perch (Lates niloticus). Food Chemistry. 2004;86(3):325-332.

24. Beltrán M, Marcilla A, Garcia JC. Fourier-tranform infraredspectrocopy applied to the study of PVC decomposition. European Polymer Journal. 1997;33(7):1135-1142.

25. Ramesh S, Leen KH, Kumutha K, Arof AK. FTIR studies of PVC/PMMA blend based polymer electrolytes. Spectrochimica Acta Part A: Molecular and Biomolecular Spectroscopy. 2007;66(4-5):1237-1242. 